\title{
E-learning Content and Knowledge Characteristics Empirical Case Study
}

\author{
Asmahan Majed Altaher \\ Applied Science University, Amman, Jordan
}

\begin{abstract}
Knowledge characteristics are essential in leveraging knowledge value; they are more evident with explicit knowledge ease of use, transfer, and mobility. However, tacit knowledge exhibits other characteristics, in order to contribute and transfer. The aim of this article is to show how knowledge management has a positive contribution on e-learning contents through a model proposed to support this perception. The article focuses on the characteristics of knowledge and its effect on e-learning content, the nature of knowledge, and the quality of content in e-learning system, in order to improve the content of the knowledge and facilitate the e-learning system usage, especially that knowledge and e-learning have much to offer each other. The result lead recommends that the education institutions should understand the knowledge characteristics and the potential techniques that support transfer knowledge as Edraak Jordanian initiative goes on doing, in addition, the education institutions should understand which types of knowledge can by articulated or which knowledge can be through practices or apprenticeship. Finally, the education institutions need to organize and categorize the knowledge so that it can retrieve when it's needed, Edraak initiative is successful to introduce many courses in deferent topics and the content was clear and helpful for many learners to have training course and keep continuance learning in all society.
\end{abstract}

Keywords: knowledge characteristics, e-learning content, explicit knowledge, tacit knowledge, codify-ability, explicitness, teach-ability

\section{Introduction}

Knowledge management is the access to experience and expertise that creates new capabilities enables superior performance and encourages innovation (Maryan \& Dorothy, 2001). Knowledge management is concerned with the exploitation and development of the knowledge assets, managing entails processes associated with the identification, and sharing and creation of knowledge. Knowledge management is likely to view knowledge as an asset to develop organizational norms and values, which support the creation and sharing knowledge (Anantatmula \& Stankosky, 2008). Many education institutions start to create their knowledge repositories in order to support learning process and the new e-learning content. The education institutions offering degree courses in new media produce with basic competencies in standard graphic and authoring tools, rather than the specific mixture of learning-related (Trentin, 2010). Knowledge and skills are required to carry out effective e-learning content development (Belisle, 2008)

\footnotetext{
Asmahan Majed Altaher, associate professor. Applied Science Private University, Amman, Jordan.

Correspondence concerning this article should be addressed to Asmahan Majed Altaher, P.O. Box: 166-11391, Amman, Jordan. E-mail: a_altaher68@hotmail.com.
} 
E-learning can be considered as a process of combining content with support and community. Networked technologies are used to create, foster, deliver, and facilitate learning anytime and anywhere (Holsapple \& Joshi, 1999). In addition to providing delivery mechanisms for content, internet tools are also used to mentor and monitor learners, facilitate interaction among dispersed learners, introduce subject matter experts, evaluate the learning experience, and foster virtual communities among practitioners (Bassoppo-Moyo, 2006; Trentin, 2010).

The primary mission of educational institutions is the creation, preservation, integration, transmission, and knowledge application. Educational institutions are synchronized with the functionalities of knowledge management. Thus it is logical that knowledge management tools and technologies can be applied to e-learning in several ways such as e-learning portal, dynamic delivery, and presentation of the content (Coulson, 2000).

E-learning can provide a single experience and the e-learning concept can be treated as a technological advancement with advantages and disadvantages. The ability of information, knowledge, and communication technologies starts to realize its various components, formulating a wide range of applied informatics. The common practice to create an e-learning platform, adapt content or buy content, and deliver on a 24-hour basis the learning material to various learners has a justification: It provides an easy way to claim presence on e-learning irrelevant to the absence of mechanisms that exploit the value diffusion for the learners and the trainers (Sharp, 2006). The dynamic nature of learning, the different learners' preferences, the customized learning content, and the establishment of non-sequential learning scenarios seem to be crucial obstacles for the majority of e-learning platforms. From this point of view, e-learning is not an effective solution, nor a motivational driver, when people do not capitalize on its value dimension. E-learning can offer individualized, as well as group instruction, allows you to combine knowledge management, learning content in order to support the learning processes; it is not a process in itself. The key to e-learning success in an organization is to tie e-learning to the students' needs and then measure its impact on those needs (Mishra \& Ramesh, 2005; Siemens, 2004).

Knowledge content delivered through the internet is instantly updatable. E-learning allows people to keep up with the rapid changes that define the global world. In order to access the characteristics in each content area, the education institutions should find a way that develop and uphold the quality of the educational experience to provide valuable content, providing valuable content is accomplished through the use of animation software and interactive multimedia, which are capable of illustrating interconnected processes within complex systems and need to course management systems that are used to create e-learning training type and delivery approach from institution to institution (Widding, 2007). The article was focused on the knowledge characteristics and e-learning content. Many writers believe that there is a relationship between the two concepts (Dick, L. Carey, \& J. Carey, 2005). The paper is organized as follows: In first section, it is introduced literature review; the second section will be about research framework and discuss-phase of this framework; next, it is about methodology, and then statistical analysis; and finally the conclusions.

\section{Knowledge Characteristics and E-learning Content Framework}

E-learning content will explain through deferent example from Edraak initiative. The three types of the knowledge characteristics were discussed below in the article. Next section will be about the effect of knowledge characteristics e-learning (Figure 1). 


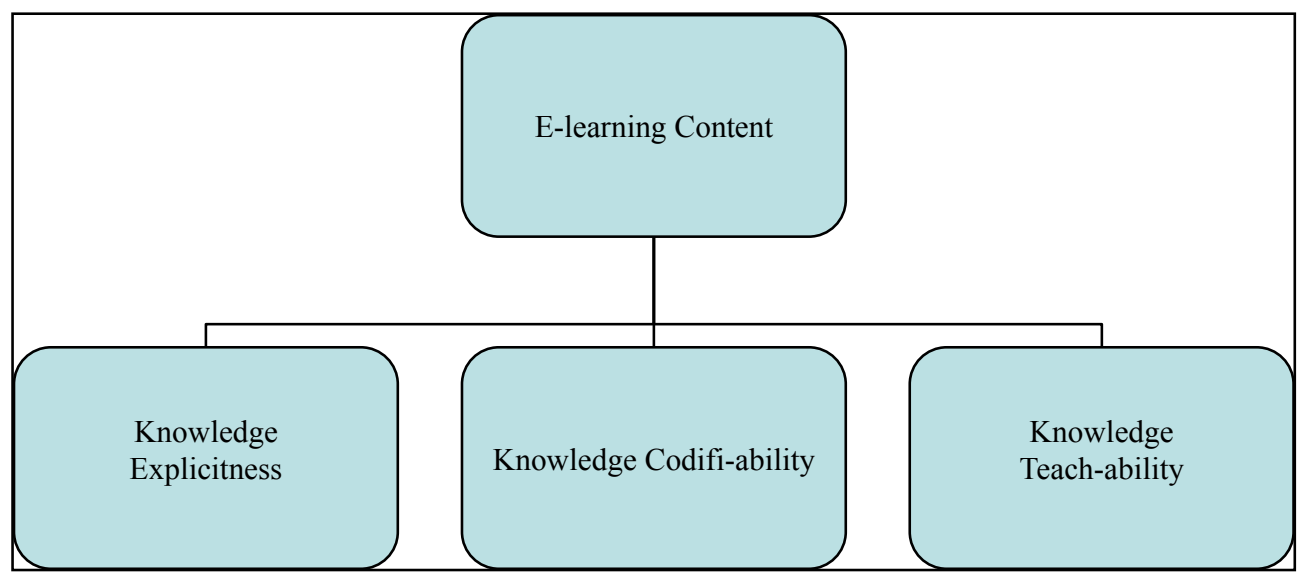

Figure 1. Framework of e-learning content and Knowledge characteristics. Source: Researcher's adapt.

\section{Effect of Knowledge Characteristics E-learning}

Knowledge characteristics and e-learning will converge into knowledge collaboration portals that will efficiently transfer knowledge in an interdisciplinary and cross functional environment. In addition, knowledge characteristics have to develop a set of content specific characteristics that demonstrate highly effective teaching and learning (Rowley, 2000). The goal of e-learning is to train adult learners by increasing and adding knowledge to their schemas. Therefore, e-learner is learner-controlled, because learners must apply their current knowledge and integrate the content elements into a learning platform that learners can access (Williams, 2007). E-learning contents are defined as those digital learning materials which are bias-free, pedagogically flexible, customisable, and accessible. E-learning may be in or out of the traditional location. It can be self-paced or may be instructor-led and synchronous. E-learning is suited to flexible learning, but it can also be used in conjunction with face-to-face teaching (Keenan \& Yao-kuei, 2006). One of the important foundation in Jordan that supports the education in Arab world is Queen Rania Foundation (QRF). It introduced Edraak initiative and was aimed to revolutionize the quality of education by introducing a massive courses online for anyone at anytime anywhere. Edraak is a massive open online course (MOOC) platform. Next section intrudes knowledge characteristics and its important in e-learning content with deferent example from Edraak initiative.

Types of the knowledge characteristics of were discussed below:

- explicitness;

- codify-ability;

- teach-ability.

The education institutions purpose must adopt wide variety knowledge in e-learning, such as virtual learning, the university, and self-directed learning (Barker, 2005).

\section{Knowledge Explicitness}

There is a common view prevent that knowledge begins with an individual minds (Bassoppo, 2006). The individual or group that acts with e-learning system can always add necessary value through the interactive with a system; in order to introduce explicit knowledge to the e-learning system, the institutions should commitment to triggering new questions and enquiries, plus add a high level of content (Rowley, 2000). The system must encourage and help the student to transfer their ideas and enable them to have a knowledge, also 
the e-learning should have the ability to convert the tacit knowledge into the right content, which should connect with interactive learning system that can help to improve the student' ability, skills, and responsibilities (Goh, 2002), for example, the new MOOC platform will present the Arab world with unique and vital opportunities that can be part of a necessary revolution in education and learning. Edraak has been a pan-Arab effort meant to serve the entire Arab region. As such, the QRF has sought support from visionary leaders across the Arab world, as founding partners.

\section{Knowledge Teach-ability}

Teach-ability reflects the extent to which the knowledge can be taught to other students, through training, apprenticeship, and so on. Of course, some knowledge could be high in teach-ability (Barker, 2005), as knowledge maturing is basically the interconnection of individual learning process where knowledge is taught and learnt. Whereas immature knowledge is hard to teach, in order to increase the knowledge teach-ability, the institutions should create e-learning content transferred to student and support this system with verity tools to help students to practice themselves (Wafula, Miriti, \& Goodman, 2012). Edraak initiative allows professors to inspire thousands of Arab learners thirsting for currant and relevant content and provide education institution with an opportunity to explore realm of online education.

\section{Knowledge Codifi-ability}

Knowledge codification is about transferring the knowledge to application. The institutions should have a perspective toward the knowledge capability and determine what they need from the application. Further, researchers define codification in tow side as explicit and tacit, as regards to the knowledge types. Codification is high, when institution has tacit knowledge. The codification and diffusion knowledge can align long continuum explicitness, teach-ability (Goh, 2002).

Exploring the knowledge codification is important in order to create the e-learning system. Codification is treated as a multidimensional construct. They focus on three different forms of codification: knowledge encoded in codes and figures form (Maryan \& Dorothy, 2001); knowledge encoded in words and texts which are less abstract form; and knowledge encoded in pictures and images which are the least abstract form. They find that the effect of knowledge codification on organizational is moderated by a strategic content. The literature about knowledge codification, diffusion, and application reveals some issues that need to be reviewed.

The knowledge codification needs to be specific and have many details, when explaining knowledge flow in an institution (Keenan \& Yao-kuei, 2006). The example here from Edraak initiative gives great opportunity for institutions to locate and attract talent from across the region.

\section{Design and Methodology}

The data and information are developed as the following action plan:

(1) To ensure that knowledge characteristics is important to support e-learning content with regard to knowledge management;

(2) To identify e-learning content ensures knowledge linked to objectives and targets of education and learning plans.

To collect data, researcher conducted primary and secondary resource. The researcher adapts the descriptive studies, because it can answer questions such as "what is" or "what was". The researcher, involving data collection and using existing records to collect data important to emphasize research methods, can describe 
a set of observations or the data collected (Sekaran, 2003). The article adapts the descriptive study, which focuses on important area related to knowledge characteristics and e-learning content. It is a kind of collaborative research's efforts. In order to spot in e-learning, the researcher presents foundation that supports the field called Edraak as the case study. The researcher used deferent web site, scientific previous books, and articles related.

\section{Result and Discussion}

Knowledge and electronic learning is an important research area, as the emerging of new landscape of knowledge economy and requiring integration of knowledge and learning (Coulson, 2000). Knowledge management tools and technologies must be applied to e-learning in several ways, such as e-learning portal, dynamic delivery, and presentation of the content. In nowadays, knowledge is the power and the education institutions should take their responsibility to help student and society development. To achieve this goal, they should start to support people for continues learning through using e-learning systems, and in order to make the learning effective and efficient, the university and education institutions start to take care of the learning content and the nature of knowledge (Goh, 2002). The e-learning system must encourage and help the student to transfer their ideas, enabling them to have knowledge. It should have the ability to convert the tacit knowledge into the right content and this is a need to connect the learners with interactive learning system which can help to improve the student's ability, skills, and responsibilities. Knowledge built the history, because the education sector starts to create new plans for disseminating knowledge by focusing on the characteristics of the knowledge to make it effective. The education institutions should understand the type of knowledge and how it can be useful, teachable, and easy for coding. To draw a helpful plan in developing learners, the institutions should have a perspective toward the knowledge capability and determine what it needs. In Jordan, Edraak, which helped the e-learning sector, represents a good example to disseminate and share knowledge for student and learners in all society.

\section{Conclusions}

The article introduced important concepts area of the field of e-learning content and knowledge characteristics through retrieving the previous resource and articles. Knowledge is very important and the student work hard to accumulate high levels of knowledge, in order to achieve this goal. The learning institutions care about the knowledge and make it explicate and available, whenever and wherever it needs. Knowledge should be codify-ability, explicitness, teach-ability, and suitable for new forms of learning like e-learning and distance learning. E-learning is a fundamental area in the new world, because of that, the research was focused on Edraak initiative as a case example of e-learning content. The initiative was granted by the QRF, aiming to support and revolutionize the quality of education and continues learning. The writer recommends that the education institutions should understand the knowledge characteristics, in order to make the e-learning content rich, achiness, and depth. To aggregate a high level of e-learning content, Edraak initiative introduces many courses in deferent topics and the content was clear and helpful for many learners to have training courses and keep continuance learning.

\section{Reference}

Anantatmula, S., \& Stankosky, M. (2008). KM criteria for different types of organizations. Int. J. Knowledge and Learning, 4(1), $18-35$. 
Barker, P. (2005). Knowledge management for e-learning. Journal of Innovation in Education and Teaching International, 42(2), 111-121.

Bassoppo-Moyo, T. C. (2006). Evaluating e-learning: A front-end, process and post hoc approach. International Journal of Instructional Media, 33(1), 7-7.

Belisle, C. (2008). E-learning and intercultural dimensions of learning theories and teaching models. Retrieved from www.elearningpapers.eu.No.7.

Coulson, C. (2000). Developing a corporate learning strategy. Industrial \& Commercial Training, 32(3), 84-88.

Dick, W., Carey, L., \& Carey, J. (2005). The systematic design of instruction (6th ed.). New York: Holt, Rinehart and Winston, Inc..

Goh, S. (2002). Managing effective knowledge transfer: An integrative framework and some practice implications. Journal of Knowledge Management, 6(1), 23-30.

Holsapple, C. W., \& Joshi, K. D. (1999). Description and analysis of existing knowledge management frameworks. Proceedings from 32nd Hawaii International Conference on Systems Sciences. Retrieved from http://www. Computerororg

Keenan, A. P., \& Yao-kuei, L. (2006). The influence of system characteristics on e-learning use. Computers \& Education, 47(2), 222-244.

Maryan, A., \& Dorothy, E. L. (2001). Management and knowledge management systems: Conceptual foundations and research issues. MIS Quarterly, 25(1), 107-136.

Mishra, S., \& Ramesh, S. C. (2005). Interactive multimedia in education and training. Hershey: Idea Group Publishing.

Rowley, J. (2000). Is higher education ready for knowledge management? International Journal of Educational Management, 14(7), 325-333.

Sekaran, U. (2003). Research methods for business (4th ed.). Hoboken: John Wiley \& Sons.

Sharp, V. (2006). Computer education for teachers: Integrating technology into classroom teaching (5th ed.). New York: McGraw-Hill.

Siemens, G. (2004). Connectivism: A learning theory for the digital age. Retrieved from http://www.elearnspace.org/Articles

Trentin, G. (2010). Networked collaborative learning: Social interaction and active learning. Cambridge: Woodhead/Chandos Publishing Limited.

Wafula, F. N. Miriti, E. M. \& Goodman, C. A. (2012). Examining characteristics, knowledge and regulatory practices of specialized drug shops in Sub-Saharan Africa: A systematic review of the literature. Health Services Research, 12, $223-223$.

Widding, O. (2007). Entrepreneurial knowledge management and sustainable opportunity creations: A conceptual framework. Int. J. Learning and Intellectual Capital, 4(1-2), 187-202.

Williams, C. (2007). Transfer in context: Replication and adaptation in knowledge transfer relationships. Strategic Management Journal, 28, 867-889. 